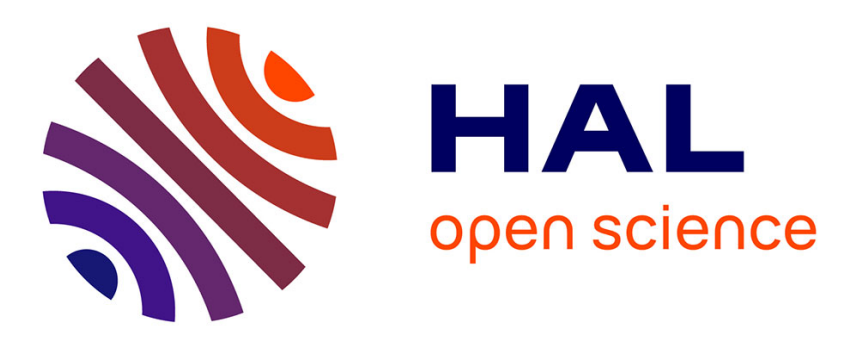

\title{
Phenomenological Studies for Optimizing Subsonic Underwater Discharges
}

Yoan Bacqueyrisses, Thierry Reess, Viviane Tchalla, Bucur M Novac, Antoine Silvestre de Ferron

\section{- To cite this version:}

Yoan Bacqueyrisses, Thierry Reess, Viviane Tchalla, Bucur M Novac, Antoine Silvestre de Ferron. Phenomenological Studies for Optimizing Subsonic Underwater Discharges. IEEE Transactions on Plasma Science, 2021, 49 (11), pp.3615 - 3624. 10.1109/tps.2021.3121025 . hal-03468986

\section{HAL Id: hal-03468986 https: / hal-univ-pau.archives-ouvertes.fr/hal-03468986}

Submitted on 7 Dec 2021

HAL is a multi-disciplinary open access archive for the deposit and dissemination of scientific research documents, whether they are published or not. The documents may come from teaching and research institutions in France or abroad, or from public or private research centers.
L'archive ouverte pluridisciplinaire $\mathbf{H A L}$, est destinée au dépôt et à la diffusion de documents scientifiques de niveau recherche, publiés ou non, émanant des établissements d'enseignement et de recherche français ou étrangers, des laboratoires publics ou privés. 


\title{
Phenomenological Studies for Optimizing Subsonic Underwater Discharges
}

\author{
Yoan Bacqueyrisses $^{(}$, Thierry Reess ${ }^{(}$, Antoine Silvestre de Ferron $^{(}$, Viviane Tchalla, \\ and Bucur M. Novac ${ }^{\circledR}$, Senior Member, IEEE
}

\begin{abstract}
Powerful subsonic underwater discharges are used as a tool in various industrial applications. The aim of this article is to find the essential design parameters required for a pulsedpower system to efficiently drive such discharges. Using different capacitor banks and electrode geometries, a large number of studies were conducted in an effort to better understand the phenomenology of the discharge. Without developing a numerical model for the underwater plasma discharge, the phenomenological studies clearly demonstrated that the maximum pressure that can be generated depends on the discharge current, the distance between the electrodes, and the characteristic time of the discharge. The results of this work will allow the design of efficient pulsed-power-driven strong pressure impulse systems.
\end{abstract}

Index Terms-Pulsed-power, pulsed pressure, underwater discharges.

\section{INTRODUCTION}

$\mathbf{H}$ IGH-VOLTAGE, high-power underwater electric discharges have been studied for several decades. Two main regimes are known for such discharges: subsonic, where an oscillating bubble is created, and supersonic, a streamer-based phenomenon (see [1] for more details about the two different regimes). The present article deals only with high-energy, high-power subsonic techniques that use a relatively slow (tens of microseconds) application of a high voltage across a pair of electrodes immersed in water, resulting in a Joule-heated creation of a gas bubble through which electrical breakdown occurs.

A large number of important industrial applications of subsonic high-energy, high-power discharge techniques are well-known [2]-[22], such as underwater welding and electrohydraulic forming, shockwave generation for industrial sludge treatment, demolition, removal of foreign deposits from pipe walls, material fragmentation, separation, reduction and recycling, and finally ore separation and rock fracturing for mining

Manuscript received June 6, 2021; revised September 9, 2021; accepted October 9, 2021. This work was supported by ITHPP, France. The review of this article was arranged by Senior Editor R. P. Joshi. (Corresponding author: Antoine Silvestre de Ferron.)

Yoan Bacqueyrisses, Thierry Reess, Antoine Silvestre de Ferron, and Viviane Tchalla are with the Universite de Pau et des Pays de l'Adour, E2S UPPA, SIAME, 64000 Pau, France (e-mail: ybacqueyrisses@ithpp-alcen.fr; antoine.deferron@univ-pau.fr).

Bucur M. Novac is with the Wolfson School of Mechanical, Electrical and Manufacturing Engineering, Loughborough University, Loughborough LE11 3TU, U.K., and also with the Laboratoire des Sciences de l'Ingénieur Appliquées à la Mécanique et au Génie Électrique - Fédération IPRA, Université de Pau et des Pays de l'Adour/E2S UPPA, 64000 Pau, France (e-mail: b.m.novac@lboro.ac.uk).

Color versions of one or more figures in this article are available at https://doi.org/10.1109/TPS.2021.3121025.

Digital Object Identifier 10.1109/TPS.2021.3121025 applications such as blasting and drilling. Some of these applications are discussed in a book fully dedicated to pulsed electric breakdown of liquid phenomena [23].

Neglecting any physical phenomena related to fluid physics, such as the bubble dynamics, the articles related to the main parameters affecting the generation of peak pressure by a given pulsed-power generator are not numerous. Some works, such as those reported in [20] and [24], studied the influence of the electrical Joule energy deposited in the plasma discharge on the peak pressure using three different generators. An important finding is highlighted: the parameter "energy" is not sufficient to characterize the value of the pressure. Further studies reported in [4] and [25] proved that indeed different peak pressures can be produced with a generator, even when the same electrical energy is used. The electrical circuit used in [25] had a "bypass branch" implemented, which could be activated at any predetermined time, to stop the main current flowing through the plasma discharge. Interestingly, the results reported show that as the plasma discharge is stopped at times approaching the moment the main current reaches its (first) peak, the generated peak pressure increases. However, when the current is stopped after reaching its (first) peak, the generated peak pressure does not change much. Therefore, the results suggest a relationship between the (first) peak current and the peak pressure. The authors have not tried, however, to highlight this finding.

Other parameters affecting the peak pressure were also studied, such as the measurement distance (in [13] and [26]), the inter-electrode gap (in [20] and [26]), and the electrode polarity (in [22] and [28]).

Recently, a research program was initiated at the Université de Pau et des Pays de l'Adour, Pau, France, for applying high-energy, high-power underwater discharge techniques for industrial rock fragmentation. It is obvious that the overview of the existing (open) literature presented above does not provide all the required information on how to design the required pulsed-power source. Therefore, the main aim of the present study is, without developing a detailed numerical simulation of the dynamics of plasma discharge, to clearly define the design parameters of a pulsed-power source affecting the generation of strong pulsed pressure waves.

The article first presents a straightforward phenomenological analysis, based on a few hypotheses. Second, the experimental arrangements used during the studies, together with the corresponding diagnostics, are introduced. Third, the results of a few preliminary studies are shown to help narrowing the 
investigation domain. Fourth, the results obtained in a large number of experiments are used to validate the hypotheses on which the phenomenological model is constructed. Finally, the conclusions present the principal parameters to be observed in the design of an optimized source of strong pressure pulses driven by pulsed-power technology.

\section{Phenomenological Model}

\section{A. Electrical Power and Energy}

The instantaneous electrical power $P_{e}$ absorbed by an underwater spark discharge can be expressed as

$$
P_{e}(t)=I(t)^{2} R_{\mathrm{SD}}(t)=V_{\mathrm{SD}}(t) I(t)
$$

where $I$ is the current flowing through the circuit and $R_{\mathrm{SD}}$ is the time-dependent resistance of the underwater plasma discharge. In practice, however, the voltage measured across the underwater electrodes $V_{\mathrm{SD}}$ will always contain both the resistive and inductive terms

$$
V_{\mathrm{SD}}(t)=L_{\mathrm{SD}} \frac{d I}{d t}+R_{\mathrm{SD}} I
$$

where $L_{\mathrm{SD}}$ is the overall underwater spark self-inductance, including connectors. It is therefore more practical to avoid using the results from a voltage measurement and calculate the power using only current and resistance. The time-dependent resistance $R_{\mathrm{SD}}$ is obviously related to the detailed phenomena of heating and vaporization, i.e., bubble formation and dynamics, and can only be accurately calculated using a numerical code using magneto-hydrodynamic equations, together with an equation of state and the conductivity variation with pressure and temperature. According to literature, for example [29], the resistance of any spark gap $R_{\mathrm{SG}}$ has the form

$$
R_{\mathrm{SG}}(t)=B \frac{d}{\sqrt{\int_{0}^{t} I(t)^{2} d t}}
$$

where $B$ is a constant and $d$ is the inter-electrode gap. According to [30], the change in an underwater spark resistance from an extremely high value, corresponding to the initial prebreakdown phase, down to the low value of the heated plasma channel is extremely fast, well under $1 \mu \mathrm{s}$. Therefore, for all practical considerations related to slow time-varying currents like those generated in the present subsonic discharges with a characteristic discharge time of many microseconds, the underwater spark resistance can be considered as a constant [31]. Using this (first) hypothesis, the resistance of the underwater spark (plasma) discharge $R_{\mathrm{SD}}$ will be simply considered as

$$
R_{\mathrm{SD}}=\frac{d}{\sigma \pi a^{2}}
$$

where $\sigma$ is the plasma conductivity and $a$ is the plasma channel radius. Consequently, the instantaneous electrical power is

$$
P_{e}(t)=I(t)^{2} \frac{d}{\sigma \pi a^{2}}
$$

while the total (constant) Joule energy absorbed during a shot, $W_{e}$, is given by the power integral

$$
W_{e}=\frac{d}{\sigma \pi a^{2}} \int_{0}^{t_{e}} I(t)^{2} d t
$$

where $t_{e}$ represents the time at which the electric current is negligibly small, i.e., the end of the discharge.

\section{B. Acoustical Power and Energy}

For an acoustical (mechanical) process, the instantaneous power $P_{a}$ is given by

$$
P_{a}(t)=F(t) v(t)=p(t) v(t) S
$$

where $F$ is a time-varying force, $v$ is the particle (material) time-varying velocity, and $S$ is the constant area over which the time-varying pressure $p$ is acting. For an acoustic wave traveling through a fluid, the particle velocity is given by [32]

$$
v(t)=\frac{p(t)}{\rho_{m} c}
$$

where $\rho_{m}$ is the constant mass density of the fluid and $c$ is the constant speed of sound in that fluid. Introducing (8) into (7)

$$
P_{a}(t)=p^{2}(t) \frac{S}{\rho_{m} c} .
$$

For a spherical acoustic pressure wave arriving at a distance $r$, the instantaneous power takes the form

$$
P_{a}(t)=p^{2}(t) \frac{4 \pi r^{2}}{\rho_{m} c} .
$$

Equation (10), which only applies to a spherical divergent acoustic wave, is very well-known and contains the product $p^{2}(t) r^{2}$. In case the spherical wave propagates without losses, the pressure $p$ varies with the distance from the source $r$ according to the law $p \sim 1 / r$. Therefore, the term $p^{2}(t) r^{2}$ is actually a constant. The authors have checked that indeed for distances up to about $1 \mathrm{~m}$ away from the acoustic sources used during the experimental studies presented in this work, the losses are so small that they are undetectable. The total (constant) acoustic energy generated during a shot, $W_{a}$, is given by the power integral

$$
W_{a}=\frac{4 \pi r^{2}}{\rho_{m} c} \int_{0}^{t_{a}} p^{2}(t) d t
$$

where $t_{a}$ represents the time at which the pressure impulse is negligibly small. In all that follows, the distance $r$ is a time constant and represents the distance between the spark gap (i.e., the acoustic source) and the hydrophone used to measure the pressure impulse $p(t)$.

\section{Factors Affecting the Generation of Peak Pressure}

During a shot, due to complex processes, a part of the total Joule energy is transformed into acoustical (mechanical) energy. As usual, an overall energy efficiency $\eta$ for this process can be defined as

$$
\eta=\frac{W_{a}}{W_{e}} .
$$

In our quest for the main parameters that influence the generation of the peak pressure during a shot, it is, however, more useful to introduce an ad hoc instantaneous peak power efficiency as

$$
\eta_{\text {peak }}=\frac{P_{a}^{\text {peak }}}{P_{e}^{\text {peak }}}
$$


TABLE I

Characteristics OF THE PUlSED-POWER GenERATORS

\begin{tabular}{ccccc}
\hline \hline $\begin{array}{c}\text { Gen. } \\
\text { No. }\end{array}$ & $\begin{array}{c}C \\
(\mu \mathrm{F})\end{array}$ & $\begin{array}{c}L \\
(\mu \mathrm{H})\end{array}$ & $\begin{array}{c}R \\
(\mathrm{~m} \Omega)\end{array}$ & $\begin{array}{c}\left.T^{*}\right) \\
(\mu \mathrm{s})\end{array}$ \\
\hline 1 & 1.4 & 4.5 & 225 & 15.8 \\
2 & 3.9 & 4.2 & 100 & 25.4 \\
3 & 21.2 & 4.2 & 40 & 59.3 \\
4 & 42.4 & 4.2 & 40 & 83.9 \\
\hline \hline
\end{tabular}

where

$$
P_{a}^{\text {peak }}=p_{\text {peak }}^{2} \frac{4 \pi r^{2}}{\rho_{m} c}
$$

and

$$
P_{e}^{\text {peak }}=\frac{d}{\sigma \pi a^{2}} I_{\text {peak }}^{2} .
$$

Equations (13)-(15) will allow us to determine the main parameters responsible for the generation of a peak pressure $p_{\text {peak }}$ as

$$
p_{\text {peak }}=\frac{I_{\text {peak }}}{2 \pi a r} \sqrt{\frac{\eta_{\text {peak }} \rho_{m} c d}{\sigma}} .
$$

Based on our previous experience, we will consider the (second) hypothesis that the peak power efficiency increases when the characteristic time of the discharge $t_{\text {char }}$ decreases, i.e., $\eta_{\text {peak }}=E_{f} /\left(t_{\text {char }}\right)^{\alpha}$, where $E_{f}$ is a constant that depends only on the characteristics of the fluid and the power $\alpha$ is a real positive number. Separating the fluid characteristics into $k=(1 / 2 \pi a)\left(\left(E_{f} \rho_{m} c / \sigma\right)\right)^{1 / 2}$, we finally obtain

$$
p_{\text {peak }}=k \frac{I_{\text {peak }}}{r} \sqrt{\frac{d}{\left(t_{\text {char }}\right)^{\alpha}}} .
$$

In what follows, taking into account the two hypotheses, $k$ will be considered a constant. A simplified form of (17) was considered in a preliminary work presented elsewhere [33].

The simple phenomenological model presented, based on the two hypotheses presented above, is thought to be valid for any pulsed-power generator and for most fluids. However, in what follows, the studies are concentrated on experimentally proving (17) using various capacitor banks as the pulsed-power generators and water as the working fluid. For a generator based on a capacitor bank, the characteristic discharge time in (17) is the discharge period, i.e., $t_{\text {char }}=T$.

\section{EXPERIMENTAL ARRAngEMENT AND DiAgnostiCs}

The schematic of the experimental arrangement used in the present studies is shown in Fig. 1. The structure of all the pulsed-power generators used in the present studies is straightforward and consists of a capacitor bank discharged using an in-house built trigatron. The experiments were conducted using four different generators, having different RLC characteristics as presented in Table I, where $R$ is the overall short-circuit resistance obtained with the two electrodes in direct contact, i.e., $d=0, L$ is the overall self-inductance, and $C$ is the overall capacitance. During short-circuit testing,

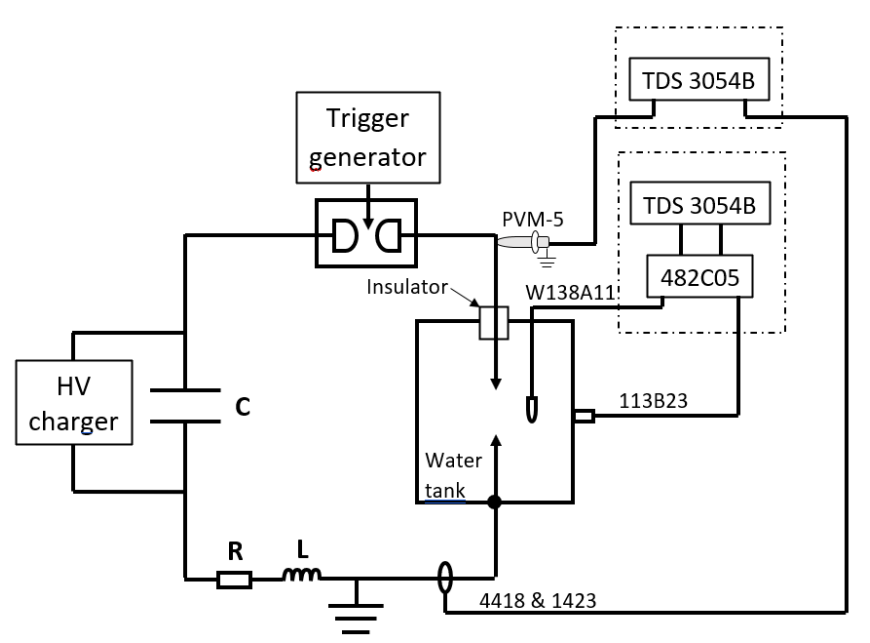

Fig. 1. Experimental arrangement (schematic). Dotted lines indicate Faraday cages.

a thin $(10 \mu \mathrm{m})$ aluminum foil was introduced between the two electrodes for improving the quality of the contact, with no light emitted being observed during the discharge (i.e., a light would indicate a poor contact between the two electrodes). Therefore, $R$ represents the total resistance of the overall circuit, including the closing switch (i.e., the trigatron operated in air), in the absence of any kind of plasma generated between the electrodes.

In all cases, the spark gap load is represented by a pair of steel electrodes (HV and ground), mounted inside a freshwater-filled metallic tank of about $600 \mathrm{~L}$. The electrode tips are exchangeable that allows accommodating electrodes having a radius from 2.5 up to $10 \mathrm{~mm}$. At the same time, the inter-electrode gap $d$ is adjustable from 3 to $8 \mathrm{~mm}$. Furthermore, the pair of electrodes can be positioned inside the tank at various places, with the distance to the nearby tank wall varying from 280 to $1320 \mathrm{~mm}$.

The voltage applied to the HV electrode is monitored using a NorthStar PVM-5 probe [34] $(60-\mathrm{kV}$ dc, $100-\mathrm{kV}$ pulsed, bandwidth $100 \mathrm{MHz}$ ), while the current flowing through the plasma discharge is accurately recorded using either a Pearson Type 4418 probe (200 kA, bandwidth $2 \mathrm{MHz}$ ) or a Pearson Type 1423 (500 kA, bandwidth $1.2 \mathrm{MHz}$ ) [35], as requested by the discharge current characteristics. The pressure impulse is detected by a system composed of a PCB Piezotronics [36] signal conditioner Type 482C05, using two hydrophones. The hydrophone model 113B23 (69 MPa, sensitivity $0.073 \mathrm{mV} / \mathrm{kPa}$, resonant frequency $\geq 0.5 \mathrm{MHz}$, rise time $\leq 1 \mu \mathrm{s}$ ) is fixed on one wall of the tank, while the hydrophone model W138A11 (69 MPa, sensitivity $0.073 \mathrm{mV} / \mathrm{kPa}$, resonant frequency $\geq 1 \mathrm{MHz}$, rise time $\leq 1.5 \mu \mathrm{s}$ ) can be positioned anywhere inside the tank. All transient signals are acquired using Tektronix TDS 3054B digital oscilloscopes, housed inside small Faraday chambers and powered from UPSs.

The tank is filled with freshwater with a conductivity of about $250 \mu \mathrm{S} / \mathrm{cm}$ and the experiments are performed at atmospheric pressure and at a temperature between $18^{\circ} \mathrm{C}$ and $20^{\circ} \mathrm{C}$. 


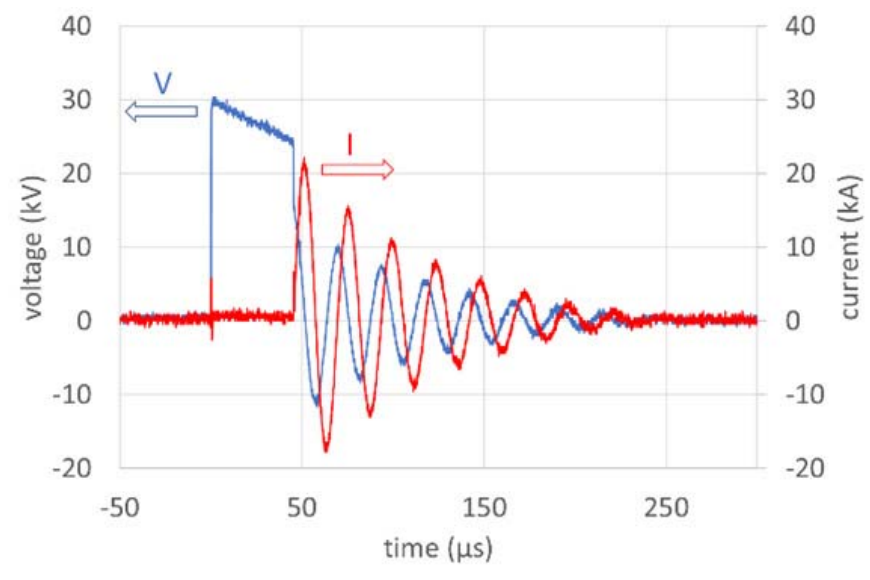

Fig. 2. Typical voltage and current waveforms recorded during a shot using generator No.2, with the capacitor initially charged to $V_{0}=30 \mathrm{kV}$ and with the distance between the electrodes $d=4.8 \mathrm{~mm}$. The breakdown takes place at $t_{b}=45 \mu \mathrm{s}$, when the voltage is only $V_{b}=23.5 \mathrm{kV}$.

\section{Preliminary StUdies}

\section{A. Typical Electric Data: Proving the First Hypothesis}

The typical current and voltage waveforms obtained during a shot with one of the generators are presented in Fig. 2. One can clearly distinguish the two phases: pre-discharge and discharge. During the pre-discharge phase, the current is very low (it cannot be observed in Fig. 2) and the voltage exponentially decays from an initial value $V_{0}$ following an $\left(R+R_{w}\right)$ C-type law, where $R_{w}$ is the pre-breakdown resistance of the underwater circuit, with very low-value currents flowing throughout the whole water tank. The breakdown takes place at a time $t_{b}$ at a breakdown voltage $V_{b}<V_{0}$. The discharge follows a sinusoidal damped shape, and it is important to note that the time dependence of the experimental current $I(t)$ can be accurately simulated with a law:

$$
I(t)=V_{b} \sqrt{\frac{C}{L}} e^{-\frac{R+R_{\mathrm{SD}}}{2 L} t} \sin \left(\frac{2 \pi t}{T}\right)
$$

where the term $\left(R+R_{\mathrm{SD}}\right)$ is a time constant (see Fig. 3). It naturally follows that the first hypothesis is true: the variation in the plasma discharge resistance takes place very fast indeed (in a few hundreds of ns), it is undetectable in Fig. 3, and therefore for all practical considerations related to the slow time-varying discharge currents generated during the present tests and for which the phenomenological model is constructed, the term $R_{\mathrm{SD}}$ will be considered as a time constant. In (18), as the circuit self-inductance $L$ is of the order of $4 \mu \mathrm{H}$, the very small self-inductance (of the order of a few $\mathrm{nH}$ ) of the inter-electrode plasma $L_{\mathrm{SD}}$ can be neglected, i.e., as $L \gg L_{\mathrm{SD}}$ it follows that $L+L_{\mathrm{SD}} \approx L$.

\section{B. Typical Pressure Data}

A typical recording of the pressure wave, corresponding to the electric data of Fig. 2, is presented in Fig. 4. The first fast-rising peak represents the direct incident pressure wave, having a peak $p_{\text {peak }} \approx 1.3 \mathrm{MPa}(13 \mathrm{bar})$. The latter pressure waveform oscillations are due to reflections from the tank's walls.

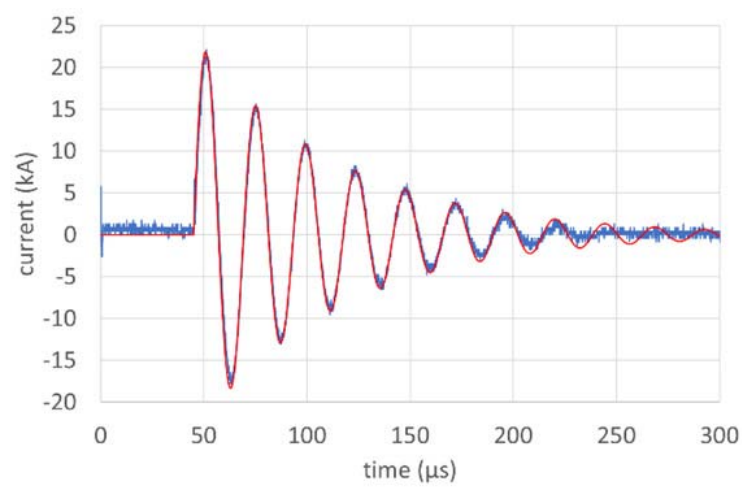

Fig. 3. Comparison between the experimental current waveform of Fig. 2 and the current calculated with (18), with $R_{\mathrm{SD}}=10 \mathrm{~m} \Omega$. As for obtaining a perfect fit (the theoretical prediction and the experimental data are indistinguishable), the term $R_{\mathrm{SD}}$ is not required to vary during the discharge, and the first hypothesis of the model is thus proven.

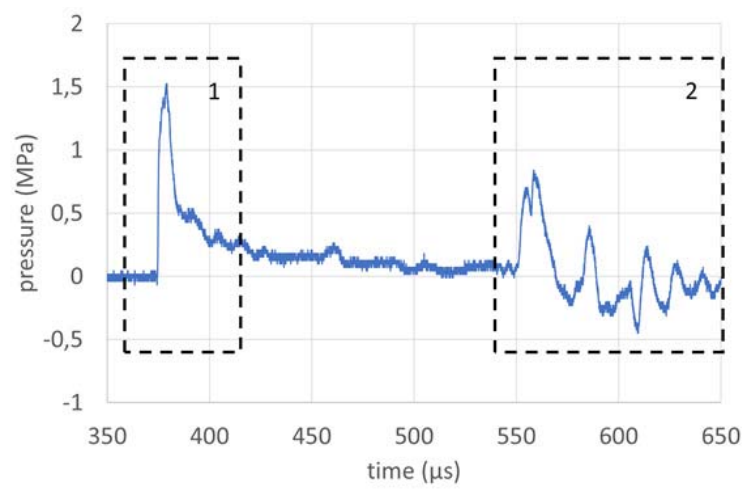

Fig. 4. Typical pressure waveforms recorded by the W138A11 hydrophone during the shot corresponding to the electric data in Fig. 2. The time origin corresponds to the beginning of the discharge in Fig. 2. The highlighted parts correspond to: 1 . the incident pressure wave and 2. the pressure due to reflections from the tank's walls.

TABLE II

End Electrode Radi For the PAirs of Electrodes Used in TESTS

\begin{tabular}{ccccc}
\hline \hline $\begin{array}{c}\text { Electrode } \\
\text { shape for the } \\
\text { pair: }\end{array}$ & $\begin{array}{c}\text { rod- } \\
\text { rod } \\
\text { (a) }\end{array}$ & $\begin{array}{c}\text { point- } \\
\text { point } \\
\text { (b) }\end{array}$ & $\begin{array}{c}\text { bulbous- } \\
\text { bulbous } \\
\text { (c) }\end{array}$ & $\begin{array}{c}\text { point- } \\
\text { spher } \\
\text { (d) }\end{array}$ \\
\hline $\begin{array}{c}\text { Electrode end } \\
\text { radii (mm) }\end{array}$ & & & & \\
HV & 10.0 & 2.5 & 2.5 & 2.5 \\
Ground & 10.0 & 2.5 & 2.5 & 100.0 \\
\hline \hline
\end{tabular}

\section{Influence of Electrode Shape}

A preliminary study was undertaken to investigate the influence of the electrode end shape. In performing this study, various pairs of electrodes were used, having different end radii as detailed in Table II. The "rod" represents a cylindrical electrode with a hemispherical end, while the "point" has a conical end shape. The "bulbous" electrode presented in Fig. 5 was designed with the idea of reducing the chances of a random electric breakdown along the electrodes, while maximizing the chances of a breakdown between the two electrodes' end. The real electrodes are presented in Fig. 6. 


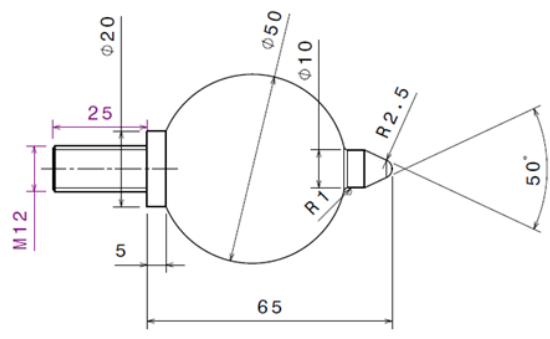

Fig. 5. Drawing of the "bulbous" electrode in Table II.

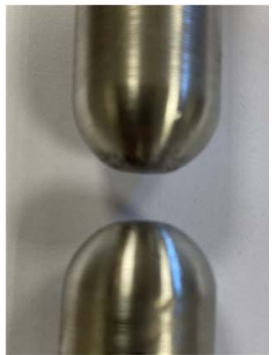

a)

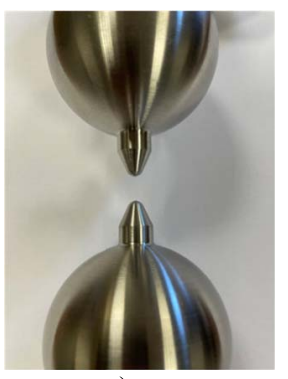

c)
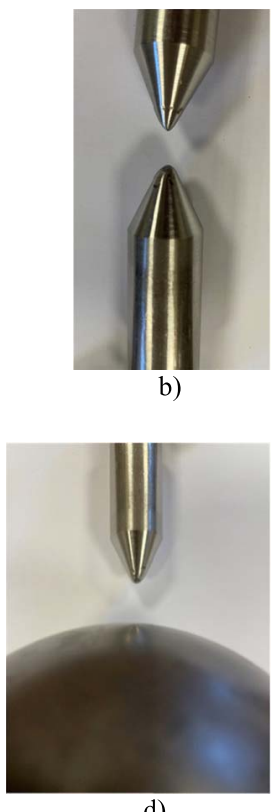

d)
Fig. 6. Photographs of the various electrode pairs used in the preliminary studies. (a), (b), (c) and (d) correspond to the pairs (a), (b), (c) and (d) described in Table II.

The results from electrostatic simulations using the CST software [37], as presented in Fig. 7, show the very different electric field distributions generated in the inter-electrode gap by the various pairs of electrodes detailed in Table II. It was thought that these differences may influence the electrical breakdown. The tests used generator No.2, with a fixed 5-mm inter-electrode gap and with the pressure measured using the W138A11 hydrophone mounted at a distance $495 \mathrm{~mm}$ from the electrodes. All pairs of electrodes in Table II were tested with basically the same result: the data in Fig. 8 clearly demonstrate that unexpectedly, the electrode shape has no influence on the peak pressure generated.

\section{Further Efforts to Reduce the Variation in Peak Pressure Data Obtained From "Identical" Tests}

As discussed above, the spark plasma resistance and therefore the constant $k$ may vary, depending on the particular 3-D plasma shape generated during a shot. It is therefore expected that results may somewhat vary, even when shots are performed under "identical" initial conditions. For example, in [38] the authors demonstrated that the electrical arc length could randomly develop along a path up to three times the inter-electrode gap. This is what was indeed observed in the present work: the peak pressures generated by "identical" shots showed an important variation. Efforts were therefore made to have identical initial conditions before each shot, such as renewing the water between the electrodes, waiting between two consecutive shots for the temperature to be stabilized, and removing any air bubbles. Further efforts consisted in using the various end electrode geometries presented in Table II to better control the area where intense pulsed electric fields (PEFs) are generated. Unfortunately, with all these efforts the results (as presented in Fig. 8) did not show any improvement, i.e., the peak pressure data generated under "identical" shots continued to be spread. In what follows, all the results presented suffer from this unwanted phenomenon.

\section{E. Influence of $H V$ Polarity}

It was anticipated that the polarity of the HV electrode may have an influence on the peak pressure generated. To investigate, experiments were performed with the capacitor of generator No.2 charged either positive or negative. For these tests, the point-sphere geometry was chosen (see Table II, pair $d$ ), as generating a highly inhomogeneous electric field distribution (see Fig. 7, d). The inter-electrode gap was set at $d=6.8 \mathrm{~mm}$ and the hydrophone mounted at a distance $r=495 \mathrm{~mm}$. Fig. 9 shows that for the same peak current, a slightly higher peak pressure is generated by a negatively charged electrode. So, we can conclude that the polarity does not have a major influence on the pressure generated.

Even if the negative polarity shows a slightly larger pressure, in what follows, for technical reasons, the experiments used only positively charged HV electrodes.

\section{Studies for Experimentally Proving (17)}

For convenience, for the studies related to the variation in the peak pressure with $r, d$, and $I_{\text {peak }}$, only generator No.2 (see Table I) was used. For the studies related to the influence of $t_{\text {char }}$, all the generators detailed in Table I were used.

Because the electrode shape has no influence on the peak pressure generated and to further simplify the studies and to minimize the unavoidable electrode erosion, in all that follows only the pair of rod electrodes (a) was used.

According to literature (e.g., see [39]), the far-field begins at a distance estimated as $\left(2 D^{2} f / c\right)$, where $D$ is the overall dimension of the source and $f$ is the detected acoustic frequency. The hydrophone W138A11 has a bandwidth limited to about $f=250 \mathrm{kHz}$ and the source dimension is estimated to be equal to the inter-electrode distance $d$ (i.e., $D=d$ ). Therefore, for the largest value of $d=7.3 \mathrm{~mm}$, the corresponding estimated far-field region begins at $34-\mathrm{mm}$ distance. In all cases, the hydrophones were placed much further away. Therefore, all the measurements were performed with the hydrophone placed in the far-field region of the acoustic source.

\section{A. Influence of $r$}

This study investigated the influence of the distance $r$ between the source (the underwater spark) and the 

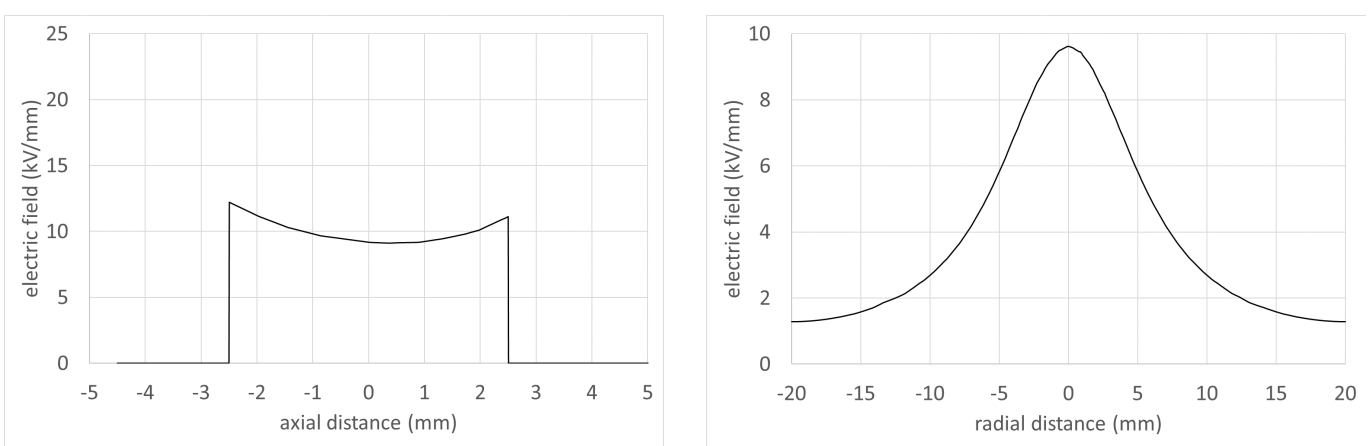

a)
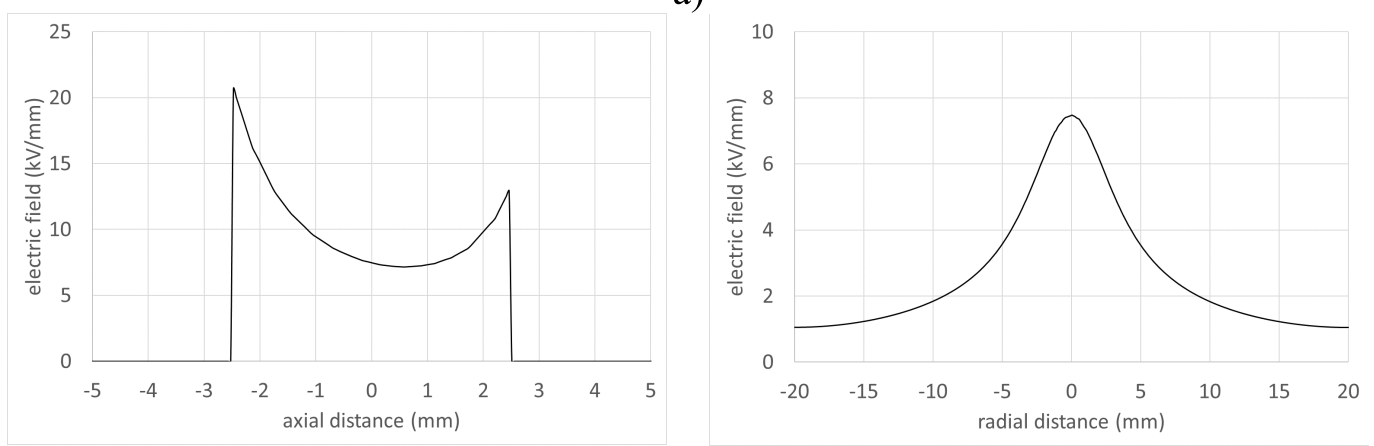

b)
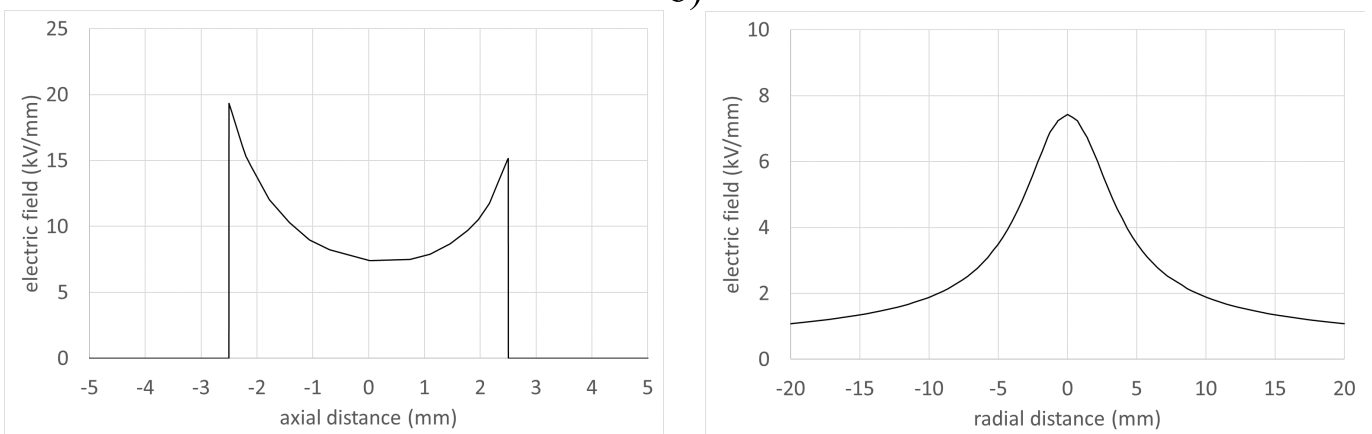

c)
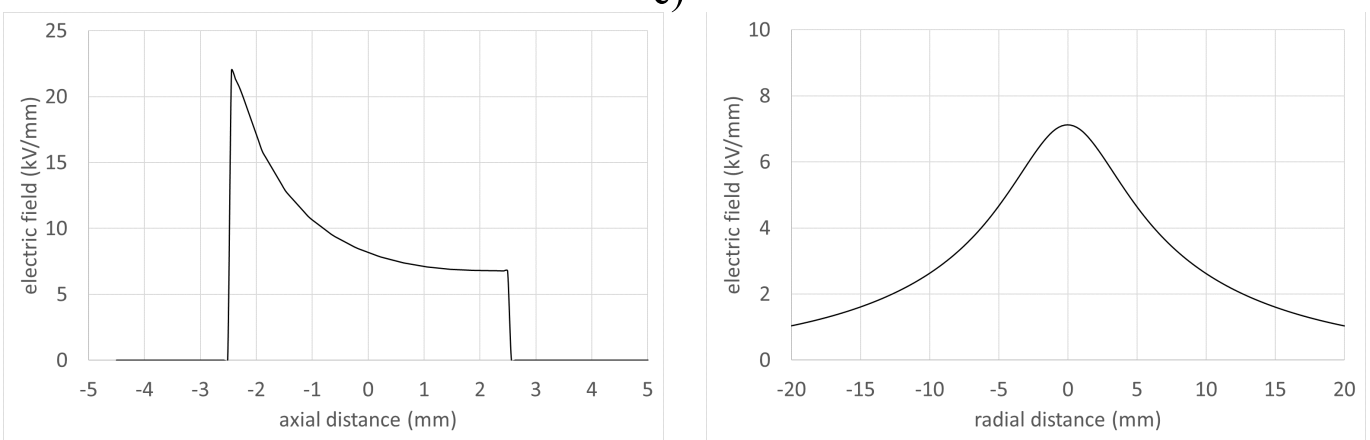

d)

Fig. 7. Axial and radial electric field distributions generated by the pairs of electrodes (a)-(d) as presented in Fig. 6 and with all details provided in Table II. Cylindrical coordinates are used, with the origin on the common axis of the two electrodes, at the inter-electrode gap center. The electrodes are positioned $5 \mathrm{~mm}$ apart, with their surface situated at $\pm 2.5 \mathrm{~mm}$ from the origin.

hydrophone. The 113B23 hydrophone was mounted at the following distances from the spark: 280, 820 , and $1320 \mathrm{~mm}$. All the tests used the same inter-electrode gap $d=4.5 \mathrm{~mm}$.

The three lines numbered 1, 2, and 3 in Fig. 10 were obtained by the least-square fit method, with the following corresponding very high Pearson's correlation coefficients:
0.982, 0.978, and 0.990, respectively. The lines represent the variation in the peak pressure with peak current, with each line corresponding to another distance to source: $r_{1}=$ $280 \mathrm{~mm}, r_{2}=820 \mathrm{~mm}$, and $r_{3}=1320 \mathrm{~mm}$, respectively. According to (17), for each line, the tangent of the angle $\delta$ between the line and the horizontal peak current axis must 


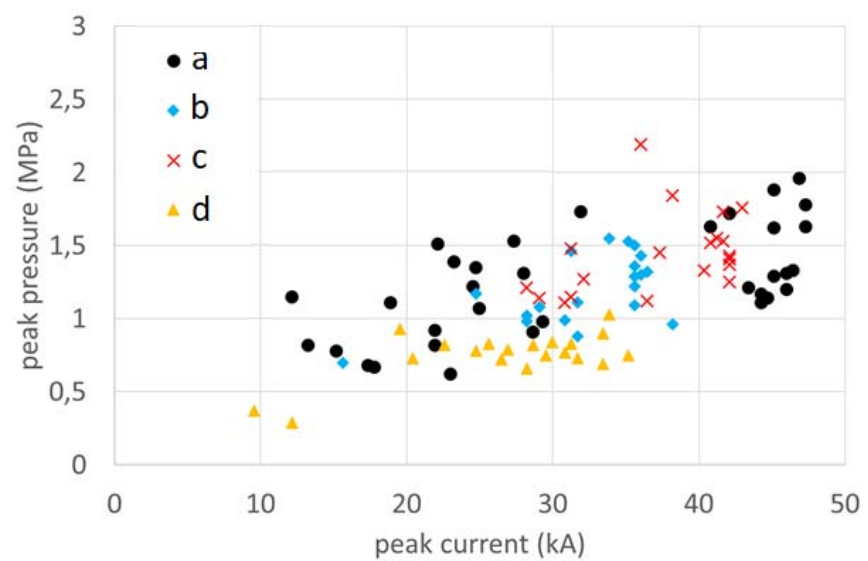

Fig. 8. Peak pressures as a function of peak current. The results were obtained using generator No.2 with the pairs of electrodes presented in Fig. 6 and Table II, mounted at a distance $d=5 \mathrm{~mm}$ apart.

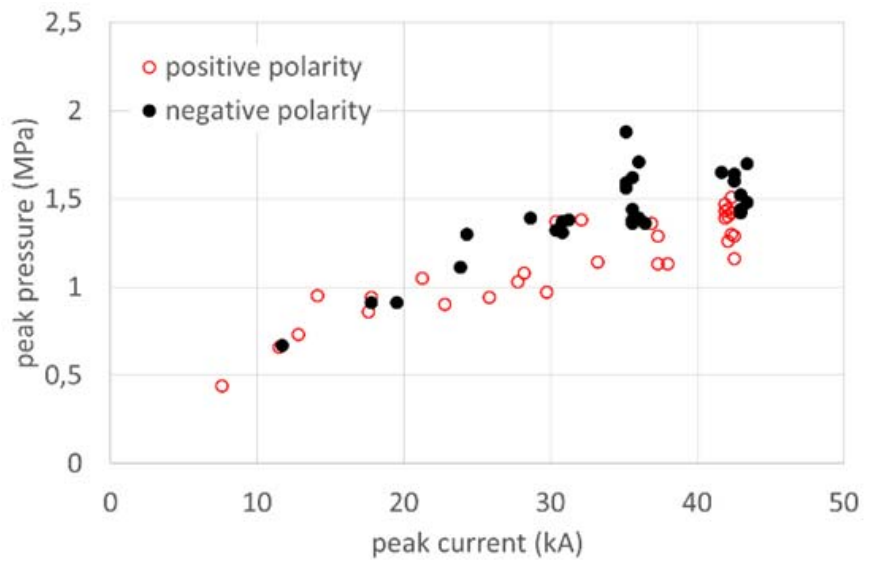

Fig. 9. Study of the influence of HV polarity. Peak pressure data obtained with the pair of electrodes $(d)$ (see Table II), having the HV electrode both positively and negatively charged.

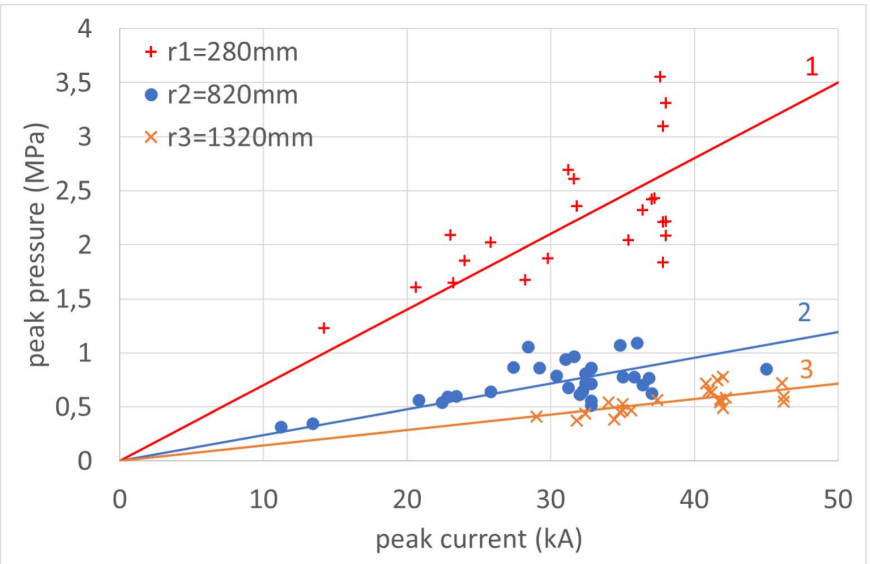

Fig. 10. Variation in the peak pressure for various peak currents flowing through the underwater spark with a constant inter-electrode distance $d=4.5 \mathrm{~mm}$. The lines obtained by the least-square fit method (Pearson's correlation coefficients: $0.982,0.978$, and 0.990 , respectively) prove that the peak pressure is proportional to the inverse of the distance $r$ between the hydrophone and the spark gap, as predicted by (17).

be proportional to $1 / r$. The ratios of these tangents for all the various combinations of lines are therefore compared

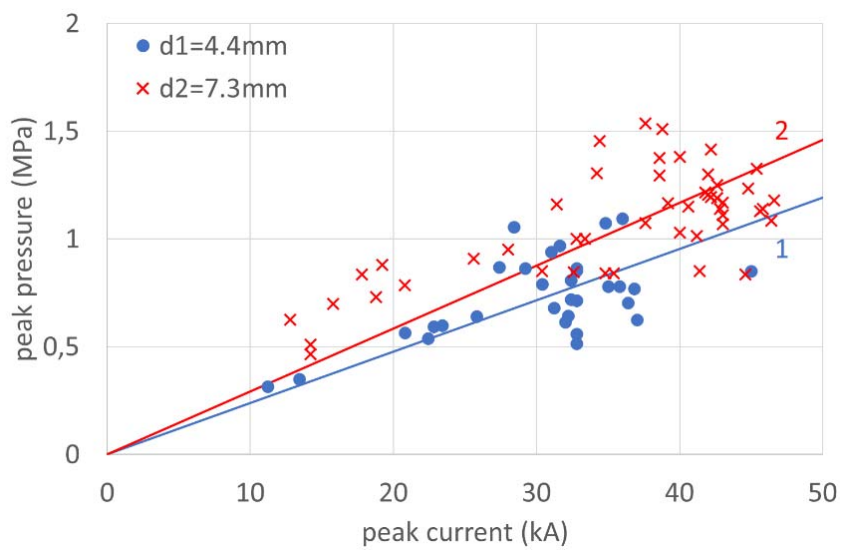

Fig. 11. Variation in the peak pressure for various peak currents flowing through the spark gap corresponding to two inter-gap distances with a constant measurement distance $r=820 \mathrm{~mm}$. The lines obtained by the least-square fit method (Pearson's correlation coefficients: 0.982 and 0.978 , respectively) prove that the peak pressure is indeed proportional to $(d)^{1 / 2}$ as predicted by (17).

below with the ratios of the corresponding distances to source:

$\tan (\delta 1) / \tan (\delta 2)=2.94$ favorably compares with $r_{2} / r_{1}=2.93$; $\tan (\delta 1) / \tan (\delta 3)=4.89$ favorably compares with $r_{3} / r_{1}=4.71$ $\tan (\delta 2) / \tan (\delta 3)=1.66$ favorably compares with $r_{3} / r_{2}=1.61$.

The conclusion is that the peak pressure indeed varies with $1 / r$ which, as expected and also as predicted by (17), is a characteristic of a spherical pressure wave in the far-field region.

\section{B. Influence of $d$}

This study investigated the influence of the inter-electrode gap $d$. The 113B23 hydrophone was used, mounted at a distance $820 \mathrm{~mm}$ from the underwater spark, with the interelectrode gap changed from 4.4 to $7.3 \mathrm{~mm}$. The two lines numbered 1 and 2 in Fig. 11 were obtained by the least-square fit method, with the following corresponding very high Pearson's correlation coefficients: 0.982 and 0.978 , respectively. The lines represent the variation in the peak pressure with peak current, with each line corresponding to another distance $d$ between the two electrodes: $d_{1}=4.4 \mathrm{~mm}$ and $d_{2}=7.3 \mathrm{~mm}$, respectively. According to (17), for each line, the tangent of the angle $\beta$ between the line and the horizontal peak current axis must be proportional to $(d)^{1 / 2}$. The ratio of the tangents for the two lines is therefore compared below with the ratio of the corresponding distances between the two electrodes:

$\tan (\beta 1) / \tan (\beta 2)=0.81$ favorably compares with $\left(\left(d_{1} / d_{2}\right)\right)^{1 / 2}=0.78$. The conclusion is that the peak pressure indeed varies with $(d)^{1 / 2}$, as predicted by (17).

\section{Influence of $I_{\text {peak }}$}

From the results obtained in the studies presented above, it is clear that the peak pressure depends on the peak current $I_{\text {peak }}$ generated during the discharge. To compare on a single graph all results obtained from these studies, in which very different 


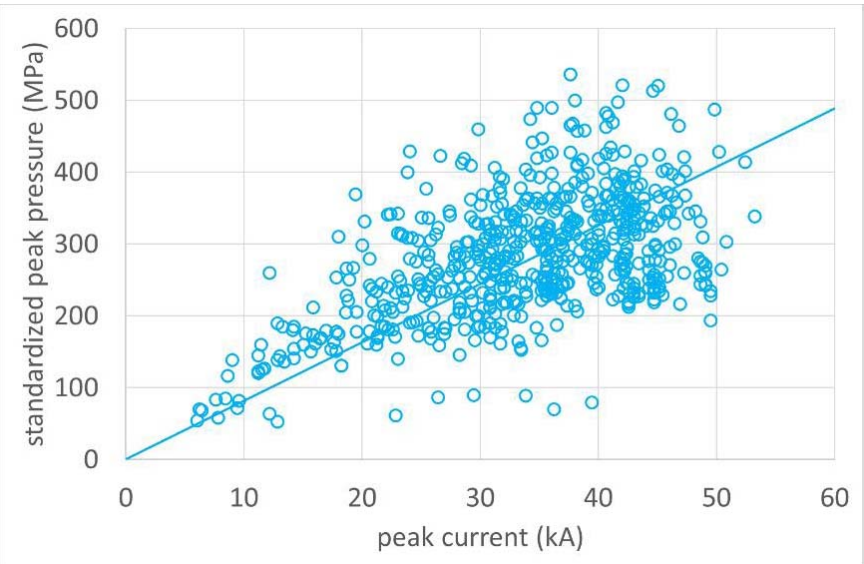

Fig. 12. Standardized peak pressure data as a function of peak current flowing through the underwater spark. The line obtained by the least-square fit method (Pearson's correlation coefficient 0.963) demonstrates the correct prediction by (17): the peak pressure is indeed proportional to the peak current.

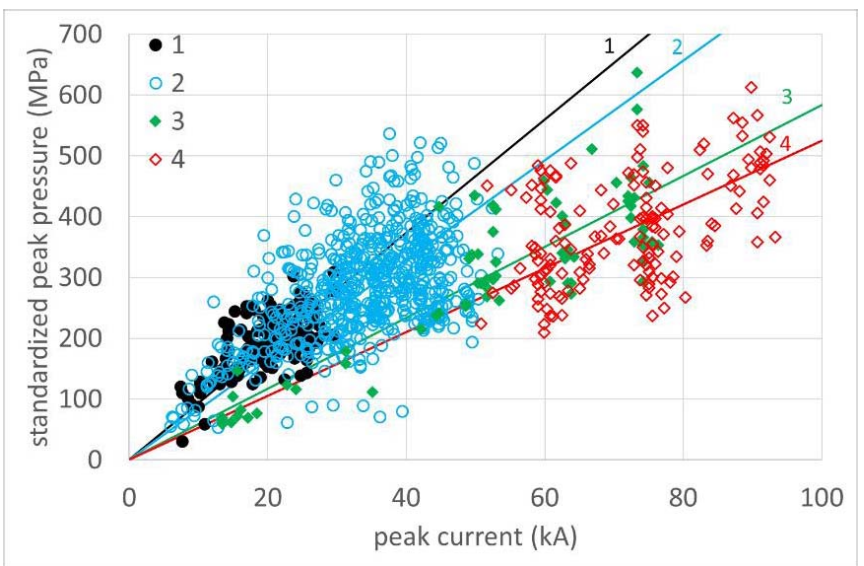

Fig. 13. Standardized peak pressure data as a function of peak current flowing through the underwater spark. For each of generators 1, 2, 3, and 4 detailed in Table I, a straight pressure-current line is obtained by least-square fit (Pearson's correlation coefficients: 0.980, 0.963, 0.980, and 0.979 , respectively). As predicted by (17), the influence of the characteristic discharge time $T$ is evident: the faster the discharge ( $T$ smaller), the larger the pressure generated.

configurations were used, a set of "standardized" pressure data $P_{\mathrm{STD} i}$ will be defined as

$$
P_{\mathrm{STD} i}=P_{\exp i} \frac{r_{i}}{\sqrt{d}_{i}}
$$

where $i=1, \ldots, N$, with $N=350$, represents the complete set of experimental data; $P_{\exp i}$ are the experimentally recorded peak pressures, and $280<r_{i}<1320 \mathrm{~mm}$ and $3<d_{i}<8 \mathrm{~mm}$ are the distance from the spark to the hydrophone and the inter-electrode gap, respectively.

Fig. 12 shows the variation in $P_{\mathrm{STD} i}$ with the corresponding peak current $I_{i}\left(5<I_{i}<55 \mathrm{kA}\right)$ flowing through the underwater spark. The least-square fit (Pearson's correlation coefficient 0.963 ) looks credible, thus proving that as predicted by (17), the peak pressure directly depends on the peak current.

\section{Influence of Characteristic Time}

By repeating the above study for the other generators presented in Table I, we can observe in Fig. 13 the influence of the characteristic time, i.e., the faster the current injected (the smaller the period $T$ ), the higher the peak pressure generated. This finally proves both the second hypothesis and the validity of (17) (Pearson's correlation coefficients 0.980, 0.963, 0.980, and 0.979 for each of generators $1,2,3$, and 4, respectively).

The power $\alpha$ can be obtained from Fig. 13 by considering for each generator $j(j=1, \ldots, 4)$ a straight pressure-current line of the form

$$
p_{\text {peak }}=a_{j} I_{\text {peak }}
$$

with $a_{j}$ being the tangent. For each pair of generators $(j, k)$, the corresponding power can be calculated as

$$
\alpha_{j, k}=\frac{\ln \left(\frac{a_{j}}{a_{k}}\right)}{\ln \left(\frac{T_{k}}{T_{j}}\right)}
$$

with $k=2, \ldots, 4(k \neq j)$ and $T_{j}$ (or $T_{k}$ ) being the period of the generator $j$ (or $k$ ) as provided in Table I. The average value of the power was found to be $\alpha=0.68$.

\section{CONCLUSION}

Four different pulsed-power generators based on the capacitor bank technology were used to demonstrate a phenomenological model that highlights the most important parameters to be observed in the design of a high peak pressure source based on underwater subsonic discharge. During the experimental studies, currents ranging from 5 to $100 \mathrm{kA}$ were generated, involving energies from $250 \mathrm{~J}$ to $25 \mathrm{~kJ}$. The peak pressures measured during the detailed experimental program requiring 1000 shots agree with the phenomenological model represented by the formula

$$
p_{\text {peak }}=k \frac{I_{\text {peak }}}{r} \sqrt{\frac{d}{T^{0.68}}} .
$$

Two final important conclusions can therefore be obtained as follows.

1) The initial energy stored in the generator is not a main parameter.

2) The two main parameters to be observed in the design of a generator are: a large peak current and a fast characteristic discharge time.

The decrease in the discharge time, while maintaining a large current, can be achieved using a smaller value for the capacitance while at the same time increasing the breakdown voltage. If we consider $I_{\max } \sim V_{b}$ and $d \approx V_{b} / E_{b}$, where $E_{b}$ is the characteristic electric field breakdown of the fluid, the peak pressure depends on the breakdown voltage as $p_{\text {peak }} \sim V_{b}^{3 / 2}$. The ideal pulsed-power generator should therefore generate a fast discharge, at a very large current and voltage.

The model suggested seems to be applicable for the range of currents from about $1 \mathrm{kA}$ to a few hundreds of kiloamperes.

\section{ACKNOWLEDGMENT}

The authors would like to thank Prof. L. Pecastaing, R. Tujague, and A. Morell for useful discussions and insight. 


\section{REFERENCES}

[1] E. Gidalevich and R. L. Boxman, "Sub- and supersonic expansion of an arc channel in liquid," J. Phys. D: Appl. Phys., vol. 39, no. 4, pp. 652-659, Feb. 2006, doi: 10.1088/0022-3727/39/4/010.

[2] Bmax. Electro-Hydraulic Forming. Accessed: 2021. [Online]. Available: https://www.bmax.com/technology/electro-hydraulic-forming/

[3] J. Hofmann and T. H. G. G. Weise, "Pulsed power technologies for commercial material reduction and crushing applications," in Proc. 11th IEEE Int. Pulsed Power Conf., Baltimore, MD, USA, Jun./Jul. 1997, pp. 203-207.

[4] K. J. Touryan, L. A. Touryan, and J. W. Benze, "An innovative use of pulsed power technology for separation of minerals from ores," in Proc. 8th IEEE Int. Conf. Pulsed Power, San Diego, CA, USA, Jun. 1991, pp. $90-93$

[5] G.-H. Rim, C.-H. Cho, H.-S. Lee, and E. P. Pavlov, "An electric-blast system for rock fragmentation," in Proc. 12th IEEE Int. Pulsed Power Conf., Monterey, CA, USA, Jun. 1999, pp. 165-168.

[6] S. Pronko, G. Schofield, M. Hamelin, and F. Kitzinger, "Megajoule pulsed power experiments for plasma blasting mining applications," in Proc. 9th IEEE Int. Pulsed Power Conf., Albuquerque, NM, USA, Jun. 1993, pp. 11-18.

[7] I. V. Lisitsyn, H. Inoue, S. Katsuki, H. Akiyama, and I. Nishizawa, "Drilling and demolition of rocks by pulsed power," in Proc. 12th IEEE Int. Pulsed Power Conf., Monterey, CA, USA, Jun. 1999, pp. 169-172.

[8] S. I. Krivosheev, N. V. Korovkin, V. K. Slastenko, and S. G. Magazinov, "Destruction of brittle materials by microsecond pressure pulses at their formation by magnetic pulse method," Int. J. Mech., vol. 9, pp. 293-299, Oct. 2015.

[9] N. V. Voitenko, A. S. Yudin, and N. S. Kuznetsova, "Evaluation of energy characteristics of high voltage equipment for electro-blasting destruction of rocks and concrete," J. Phys., Conf. Ser., vol. 652, Nov. 2015, Art. no. 012011.

[10] Z. Cai, H. Zhang, K. Liu, Y. Chen, and Q. Yu, "Experimental investigation and mechanism analysis on rock damage by high voltage spark discharge in water: Effect of electrical conductivity," Energies, vol. 13, no. 20, p. 5432, Oct. 2020.

[11] P. T. Mativenga, N. A. Shuaib, J. Howarth, F. Pestalozzi, and J. Woidasky, "High voltage fragmentation and mechanical recycling of glass fibre thermoset composite," CIRP Ann., vol. 65, no. 1, pp. 45-48, 2016.

[12] V. B. P. Sunka, "Mutual interaction of two successive shock waves focused to a common focal point," in Proc. Conf. Rec. 26th Int. Power Modulator Symp., High-Voltage Workshop, San Francisco, CA, USA, May 2004, pp. 296-299.

[13] Y. Xiao, W. House, E. Unal, and M. Soliman, "Pulsed power plasma stimulation technique-Experimental study on single pulse test for fractures initiation," presented at the 6th Unconventional Resour. Technol. Conf., Houston, TX, USA, Jul. 2018.

[14] D. Bian, J. Zhao, S. Niu, and J. Wu, "Rock fracturing under pulsed discharge homenergic water shock waves with variable characteristics and combination forms," Shock Vib., vol. 2018, pp. 1-11, Apr. 2018.

[15] K. Lee, K.-J. Chung, Y. S. Hwang, and C. Y. Kim, "Underwater spark discharge with long transmission line for cleaning horizontal wells," J. Appl. Phys., vol. 121, no. 24, Jun. 2017, Art. no. 243302.

[16] N. Boussetta et al., "Scale-up of high voltage electrical discharges for polyphenols extraction from grape pomace: Effect of the dynamic shock waves," Innov. Food Sci. Emerg. Technol., vol. 16, pp. 129-136, Oct. 2012.

[17] W. Chen, "Experimental study on an alternative oil stimulation technique for tight gas reservoirs based on dynamic shock waves generated by pulsed arc electrohydraulic discharges," J. Petroleum Sci. Eng., vols. 88-89, pp. 67-74, Jun. 2012.

[18] D. Dobrynin, R. Rakhmanov, and A. Fridman, "Nanosecond-pulsed spark discharge plasma in liquid nitrogen: Synthesis of polynitrogen from $\mathrm{NaN}_{3}$,"J. Phys. D: Appl. Phys., vol. 52, no. 45, Nov. 2019, Art. no. 455502

[19] Y. Liu et al., "Energy transfer efficiency improvement of liquid pulsed current discharge by plasma channel length regulation method," IEEE Trans. Plasma Sci., vol. 45, no. 12, pp. 3231-3239, Dec. 2017.

[20] P. G. Rutberg, V. A. Kolikov, V. E. Kurochkin, L. K. Panina, and A. P. Rutberg, "Electric discharges and the prolonged microbial resistance of water," IEEE Trans. Plasma Sci., vol. 35, no. 4, pp. 1111-1118, Aug. 2007.

[21] L. Xiong et al., "Cyclic shock damage characteristics of electrohydraulic discharge shockwaves," J. Phys. D: Appl. Phys., vol. 53, no. 18, Apr. 2020, Art. no. 185502 .
[22] H. Zhou et al., "Generation of electrohydraulic shock waves by plasma-ignited energetic materials: III. Shock wave characteristics with three discharge loads," IEEE Trans. Plasma Sci., vol. 43, no. 12, pp. 4017-4023, Dec. 2015

[23] V. Y. Ushakov, V. F. Klimkin, and S. M. Korobeynikov, Impulse Breakdown of Liquids. Berlin, Germany: Springer, 2007.

[24] S.-G. Lee, K.-J. Chung, and Y. S. Hwang, "Correlation of the peak pressure generated by an underwater spark discharge with energy absorption in a spark channel," J. Korean Phys. Soc., vol. 66, no. 12, pp. 1845-1851, Jun. 2015.

[25] S.-W. Liu, Y. Liu, Y.-J. Ren, F.-C. Lin, H. Li, and Y. Zhao, "Analysis of shock wave induced by underwater pulsed discharge using discharge current interception," J. Appl. Phys., vol. 127, no. 14, 2020, Art. no. 143301.

[26] D. Yan, D. Bian, J. Zhao, and S. Niu, "Study of the electrical characteristics, shock-wave pressure characteristics, and attenuation law based on pulse discharge in water," Shock Vib., vol. 2016, pp. 1-11, Jan. 2016.

[27] B. Li, S. Xue, and L. Yuan, "Experimental study on pressure wave characteristics of high-voltage discharge in water with hemispherical electrodes," IEEE Access, vol. 9, pp. 87173-87181, 2021.

[28] G.-Y. Zhou et al., "Influence of voltage polarity on intensity of shock waves induced by underwater pulse discharges," in Proc. IEEE 19th Int. Conf. Dielectr. Liq. (ICDL), Manchester, U.K., Jun. 2017, pp. 1-5.

[29] A. E. Vlastós, "The resistance of sparks," J. Appl. Phys., vol. 43, no. 4, pp. 1987-1989, 1972.

[30] L. K. Warne, R. E. Jorgenson, and J. M. Lehr, "Resistance of a water spark," Sandia Nat. Lab., Albuquerque, NM, USA, Tech. Rep. SAND2005-6994, 876385, Nov. 2005.

[31] Y. Sun et al., "Impulsive discharges in water: Acoustic and hydrodynamic parameters," IEEE Trans. Plasma Sci., vol. 44, no. 10, pp. 2156-2166, Oct. 2016.

[32] L. D. Landau and E. M. Lifshitz, Fluid Mechanics, vol. 6. New York, NY, USA: Pergamon, 1987, p. 252.

[33] J. Martin, T. Reess, A. De Ferron, R. Ruscassie, and F. Rey-bethbeder, "A new formula for predicting the amplitude of the dynamic pressure wave resulting from breakdown in water gap," in Proc. IEEE Int. Power Modulator High Voltage Conf. (IPMHVC), Santa Fe, NM, USA, Jun. 2014, pp. 423-426, doi: 10.1109/IPMHVC.2014.7287301.

[34] North Star. Accessed: 2021. [Online]. Available: https://www. highvoltageprobes.com/products/high-voltage-probes/

[35] Electronics. Accessed: 2021. [Online]. Available: https://www. pearsonelectronics.com/products/wideband-current-monitors

[36] PCB Piezotronics. Accessed: 2021. [Online]. Available: https://www. $\mathrm{pcb} . \mathrm{com} /$ sensors-for-test-measurement/pressure-transducers

[37] Dassault Systemes Simulia. Logiciel D'Analyse Et De Simulation Électromagnétique (EM) 3D CST Studio Suite. Accessed: Sep. 6, 2021. [Online]. Available: https://www.3ds.com/fr/produits-etservices/simulia/produits/cst-studio-suite/

[38] Y. Liu, Z. Li, X. Li, S. Liu, G. Zhou, and F. Lin, "Intensity improvement of shock waves induced by liquid electrical discharges," Phys. Plasmas, vol. 24, no. 4, 2017, Art. no. 043510.

[39] C. A. Balanis, Antenna Theory: Analysis and Design, 3rd ed. Hoboken, NJ, USA: Wiley, 2005.

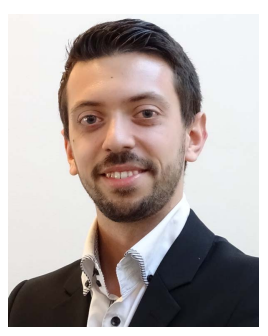

Yoan Bacqueyrisses received the M.Sc. degree in electrical engineering from the Université de Pau et des Pays de l'Adour (UPPA), Pau, France, in 2018, where he is currently pursuing the Ph.D. degree with the Department of Electrical Engineering.

His research interests include high-voltage pulsedpower systems and underwater electrical discharges for industrial and environmental application purposes. 


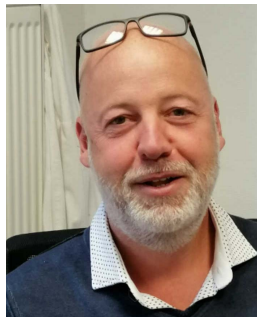

Thierry Reess was born in Pau, France, in 1968. $\mathrm{He}$ received the M.Sc. degree in plasma physics from the University of Toulouse, Toulouse, France, in 1992, and the Ph.D. degree in electrical engineering from the University of Pau, Pau, in 1996.

$\mathrm{He}$ is currently an Associate Professor with the Electrical Engineering Team of the SIAME Laboratory, University of Pau. His research interests include high-power devices, electrical discharges in gases and liquids, and environmental applications of plasma discharges.

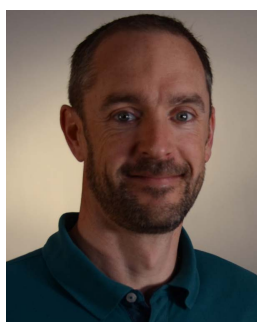

Antoine Silvestre de Ferron was born in Tarbes, France, in 1977. He received the master's degree in electrical and electronic engineering from the University of Toulouse, Toulouse, France, in 2002, and the Ph.D. degree in electrical engineering from the University of Pau, Pau, France, in 2006.

From 2006 to 2008, he was a Researcher with the Atomic Energy Commission (CEA), a French Government-Fund Technological Research Organization, Le Barp, France. He is currently an Engineer with the Electrical Engineering Laboratory, University of Pau. His research interests include pulsed-power generation, with military and civil applications and the high-voltage transient probes associated.

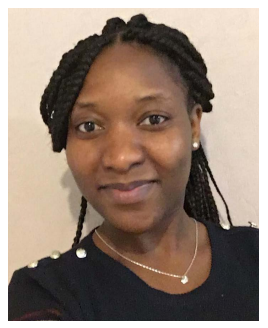

Viviane Tchalla received the M.Sc. degree in electrical engineering from the Université de Pau et des Pays de l'Adour (UPPA), Pau, France, in 2020.

She is currently an Engineer with SIAME Laboratory. Her research interests include pulsed-power systems such as Marx generators and underwater electrical discharges for biological and industrial applications.

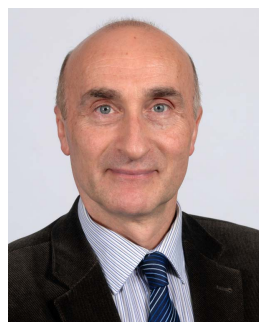

Bucur M. Novac (Senior Member, IEEE) received the M.Sc. and Ph.D. degrees from the University of Bucharest, Bucharest, Romania, in 1977 and 1989, respectively.

He joined Loughborough University, Loughborough, U.K., in 1998, where he is currently a Professor of pulsed power. He has coauthored two books on explosive pulsed power. He has published more than 200 refereed articles and conference contributions. His research interests include compact and repetitive high-power systems, explosively and electromagnetically driven magnetic flux compression generators and their applications, electromagnetic launchers, ultrafast magneto and electrooptic sensors, and 2-D modeling of pulsed-power systems.

Prof. Novac was a Voting Member of the Pulsed Power Science and Technology Committee for the IEEE Nuclear and Plasma Science Society and a member of the Organizing Committee for the IEEE International Power Modulator and High Voltage Conference. He is also a member of the International Steering Committee for the MEGAGAUSS Conference and the Euro-Asian Pulsed Power Conference. He is also a fellow of the Royal Academy of Engineering, a Chartered Engineer, and a fellow of The Institution of Engineering and Technology, U.K. He Co-Chaired the last UK Pulsed Power Symposia organised at Loughborough University. 